\title{
Investigation of Metal-Oligonucleotide Complexes by Nanoelectrospray Tandem Mass Spectrometry in the Positive Mode
}

\author{
Selina T. M. Monn and Stefan Schürch \\ Department of Chemistry and Biochemistry, University of Bern, Bern, Switzerland
}

The formation and fragmentation of multiply metal-coordinated oligonucleotides was studied by nanoelectrospray tandem mass spectrometry in the positive ion mode. Fundamental aspects of the gas-phase behavior of metal-oligonucleotide complexes are revealed. The addition of transition metal ions, such as iron(II), iron(III), and zinc(II), leads to very stable metal-oligonucleotide complexes which show heavily altered fragmentation patterns in contrast to uncomplexed oligonucleotides. The site of metal ion complexation was located by collision-induced dissociation (CID) experiments. It was found that all three metal ions investigated predominantly coordinate to the central phosphate groups of the oligonucleotides. Furthermore, it is demonstrated that the fragmentation of such complexes depends highly upon the metal ion complexed as well as on the sequence of the nucleobases in the oligonucleotide. (J Am Soc Mass Spectrom 2005, 16, 370-378) (c) 2004 American Society for Mass Spectrometry

$\mathrm{M}$ etal ions play a central role in cellular processes. Besides their function as cofactors of proteins, especially in replication, transcription, and translation, they induce folding and crosslinking of nucleic acids and result in a stabilization of these structures. Such interaction can be highly specific, like the linkage of two guanines by cisplatin complexes, or unspecific, like backbone charge neutralization on a DNA double strand [1,2]. Likewise, metal ions are involved in the stabilization of RNA, ribozymes, and telomers [3-5]. In medicine, metal ions find broad therapeutic application on DNA, as cisplatin complexes and related drugs form DNA-adducts, which act as toxic agents in tumor tissue [6]. These drugs are widely applied even though the mechanism on the molecular level is not fully elucidated yet [7]. Furthermore, there are approaches to use metal ions as markers for improved diagnostic applications [8-14]. The application of metal ions may even hold more potential, which can be taken advantage of once the interactions of metal ions with nucleic acid structures are better understood. Several NMR studies have been published with the aim of elucidating the metal ion binding pattern [15-17]. Although several approaches have been made to determine the coordination sites, no general rule on how metal ions bind to nucleic acid structures could be established yet.

The interaction of metal ions with nucleic acids has

Published online February 4, 2005

Address reprint requests to Dr. S. Schürch, Department of Chemistry and Biochemistry, University of Bern, Freiestrasse 3, CH-3012 Bern, Switzerland. E-mail: stefan.schuerch@ioc.unibe.ch also been investigated using mass spectrometry. In an early study, Christian et al. describe the influence of iron on oligonucleotides as matrix dependent [18]. Another study describes the influence of $\mathrm{Mg}^{2+}, \mathrm{Na}^{+}$, and $\mathrm{UO}_{2}{ }^{2+}$ on oligonucleotides and demonstrates that the phosphodiester groups are considered the most probable binding sites. Additionally, it is reported that these metal ions bind preferentially to the central thymine region of the analyzed octa- and dodecamer [14].

By exploring oligonucleotides with their phosphate groups completely occupied by alkali or earthalkali ions, Gross and coworkers observed that the product ion spectra of such metal complexed oligonucleotides differ significantly from the spectra of their uncomplexed analogs [19]. For the first time the fragmentation mechanism of such complexes was investigated and it was postulated that dissociation of the complexes is no longer dependent upon the proton affinity of the nucleobases, but rather on the type of the nucleobase. Also, it was remarked that metal complexed oligonucleotides show increased stability in gas phase. Another study located sodium ions at the central phosphate groups and found the position of the sodium ions to be dependent upon the number of phosphate groups [20]. Most recently, a detailed study on the interaction of deoxydinucleotides with alkali metal ions has been published by Xiang et al., demonstrating that the fragmentation of the complexed molecules depends upon the sequence, the interaction of nucleobase and metal ion, and the steric hindrance of the nucleobases [21]. A comprehensive study on iron-oligonucleotide complexes using matrix-assisted laser desorption/ionization mass spectrometry (MALDI) has been published by 
Hettich [22, 23]. Generally, published work on mass spectrometry of metal-oligonucleotide complexes focuses on electrospray ionization (ESI) and MALDI in the negative ion mode. Analyzing oligonucleotides in the positive ion mode is not common, though data have been reported previously [24-29].

In this article, we report detailed data on metaloligonucleotide complexes analyzed in the positive ion mode, since charge compensation due to the presence of positively charged metal ions greatly decreases the number of detectable complexes upon analysis in the negative ion mode.

Information on binding sites and on the altered dissociation behavior of oligonucleotides in the presence of metal ions is given, thereby furnishing an additional piece in the fundamental research on the influence of metal ions on nucleic acid structures. In addition, the influence of the metal ions on the fragmentation behavior of oligonucleotides shall be clarified to characterize specific patterns in terms of future applications, e.g., for directed fragmentation of oligonucleotides, potentially providing an aid in sequencing nucleic acid structures by mass spectrometry. In the present study, the behavior of metal-oligonucleotide complexes upon CID is elucidated in-depth with the aim to exactly determine the binding sites of the metal ions within the molecules based on the structural information gained by the product ion spectra.

\section{Experimental}

\section{Sample Preparation}

Oligonucleotides used were unmodified, single stranded oligodeoxynucleotides of the sequences TTCAT, TTGAT, TTGCT, and TTGGT. They were obtained from Microsynth (Balgach, Switzerland) and used without further purification. High purity water was purchased from Fluka (Buchs, Switzerland). Iron(II)-chloride tetrahydrate, iron(III)-chloride hexahydrate, and zinc-chloride, all in puriss p.a. quality, were also purchased from Fluka. Aqueous solutions of oligonucleotides and metal salts were prepared with concentrations of $10-40 \mathrm{pmol} / \mu \mathrm{l}$ and $200 \mathrm{pmol} / \mu \mathrm{l}$, respectively.

\section{Mass Spectrometry}

All experiments were performed on an Applied Biosystems/MDS Sciex QSTAR Pulsar hybrid quadrupoletime-of-flight mass spectrometer (Sciex, Concord, Canada), equipped with a nanoelectrospray ion source (Proxeon Biosystems, Odense, Denmark). Oligonucleotides were analyzed in the positive ion mode with a potential of 800 to $1000 \mathrm{~V}$ applied to the nanospray needle. Nitrogen was used as the curtain gas. Tandem mass spectrometric experiments were performed with the precursor ions selected within a window of \pm 1.5 $\mathrm{m} / \mathrm{z}$ units. Collision-induced dissociation was per- formed with collision energies in the range of $10-35 \mathrm{eV}$ using nitrogen as the collision gas. Calibration of the instrument was done with cesium iodide and reserpine (Fluka). The Applied Biosystems Analyst QS software package was used for data processing.

\section{Results and Discussion}

Investigation of metal-ion oligonucleotide complexes by electrospray tandem mass spectrometry was performed with a selection of four pentanucleotides containing thymine, which exhibits a relatively low proton affinity, as the terminal nucleobases. The other three nucleobases served as exchangeable units in the central part of the sequences. Relatively short oligonucleotides with asymmetric base sequence are well suited as model compounds, as their analysis results in spectra without unnecessary complexity, while they still provide the desired information regarding the fragmentation pattern.

Figure 1 shows the complexes of TTCAT in the presence of $\mathrm{ZnCl}_{2}$. Besides the peak of the uncomplexed, doubly protonated oligonucleotide, peaks corresponding to zinc-oligonucleotide complexes are present in the spectrum. Up to three $\mathrm{Zn}^{2+}$-ions are bound to the oligonucleotide and despite this varying number of metal ions, all complexes are doubly charged. Obviously, the charge state of the complexes is independent of the number of attached zinc ions. The characteristic isotopic distribution of zinc is accurately reflected by the spectrum and the isotopic patterns observed for the various complexes are in excellent agreement with the corresponding calculated distributions.

Metal-oligonucleotide complexes were selected as pre-

\section{TTCAT}

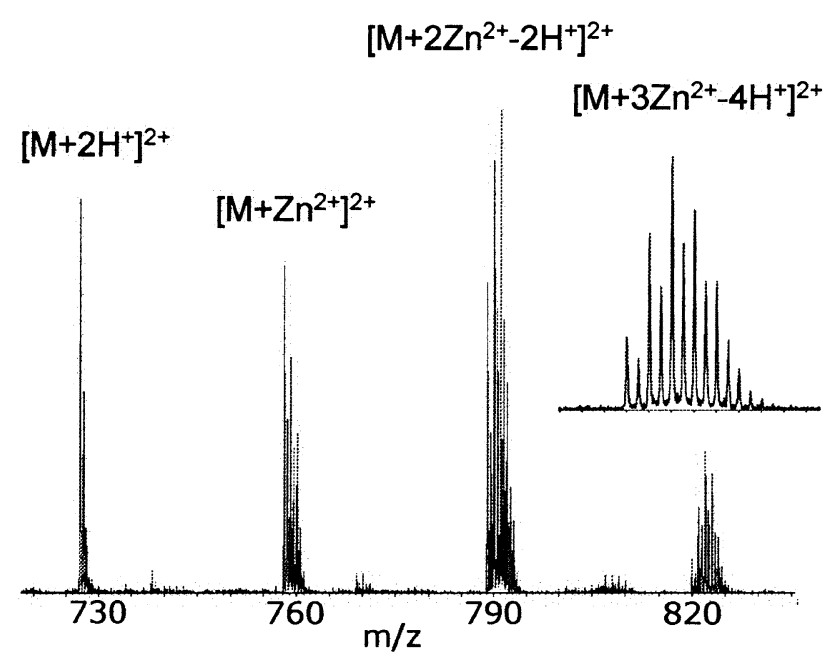

Figure 1. Section of the nanospray mass spectrum of a solution containing the oligonucleotide TTCAT and $\mathrm{ZnCl}_{2}$. The multiple metal adducts can clearly be identified. The inset shows the enlarged isotopic distribution of the triple zinc complex. 
cursor ions for CID experiments. The presence of metal ions leads to a considerable change of the fragmentation behavior. The fragmentation of $\mathrm{Fe}^{3+}-,\left[\mathrm{Fe}^{2+}\right]_{3^{-}}$, and $\left[\mathrm{Zn}^{2+}\right]_{3}$-pentamer complexes was investigated and all product ion spectra showed significant alterations of the fragment ion pattern compared to the product ion spectra of the uncomplexed pentamers. Although the ion patterns largely depend on the type of complex, they do reflect some general properties inherent to all metal-pentamer complexes. It was observed that the abundant peaks of the $\mathrm{w}_{2}$-ion, found in the product ion spectra of the uncomplexed oligonucleotides, are generally missing in the product ion spectra of the metal-oligonucleotide complexes. Also, suppression of the a- and (a-B)-ion series is increased for the complexes, when compared to the uncomplexed oligonucleotides.

The $\left(\mathrm{a}_{4}-\mathrm{B}_{4}\right)$-ions show a noticeably decreased abundance in the product ion spectra of the $\mathrm{Fe}^{3+}$-pentamer complexes and are completely missing in the product ion spectra of $\left[\mathrm{Fe}^{2+}\right]_{3}$ - and $\left[\mathrm{Zn}^{2+}\right]_{3}$-pentamer complexes. Generally, an increase of metal-complexed M-B-, $\mathrm{w}_{4^{-}}$, and $\left(\mathrm{w}_{4}-\mathrm{B}\right)$-ions in the product ion spectra of metal-ion oligonucleotide complexes is observed, thus, indicating a stabilization of the phosphate backbone by metal ions. This finding is confirmed by the presence of the metalcomplexed core fragment $\left[\mathrm{w}_{4}-\mathrm{d}_{4}\right]$ (Scheme $\mathbf{1}$ ), which is found exclusively in the product ion spectra of the metal-ion oligonucleotide complexes. The presence of the $\left[\mathrm{w}_{4}-\mathrm{d}_{4}\right]$-ion suggests that the stabilizing effect originates from the center of the molecule. This change from the product ion spectra of the uncomplexed oligonucleotide to the product ion spectra of the metal-complexed oligonucleotide is illustrated in Figure 2.

Metal-coordinated fragment ions originating from either a $\left[\mathrm{Fe}^{2+}\right]_{3}$ - or a $\left[\mathrm{Zn}^{2+}\right]_{3}$-pentamer complex always

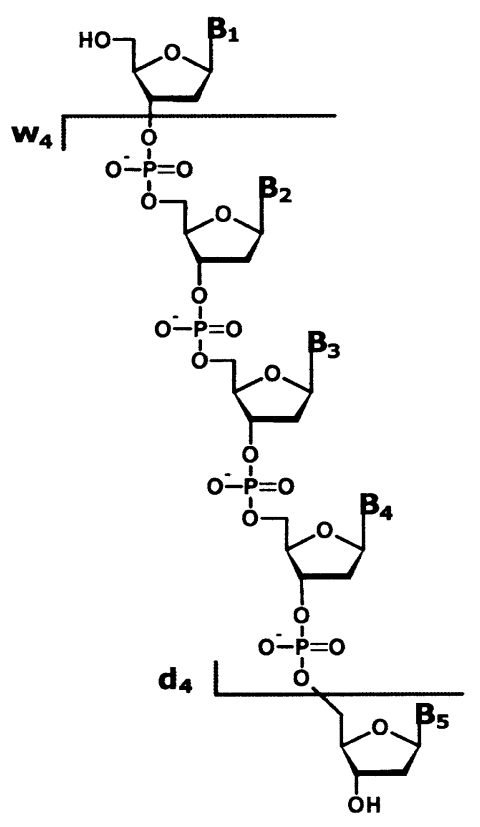

Scheme 1

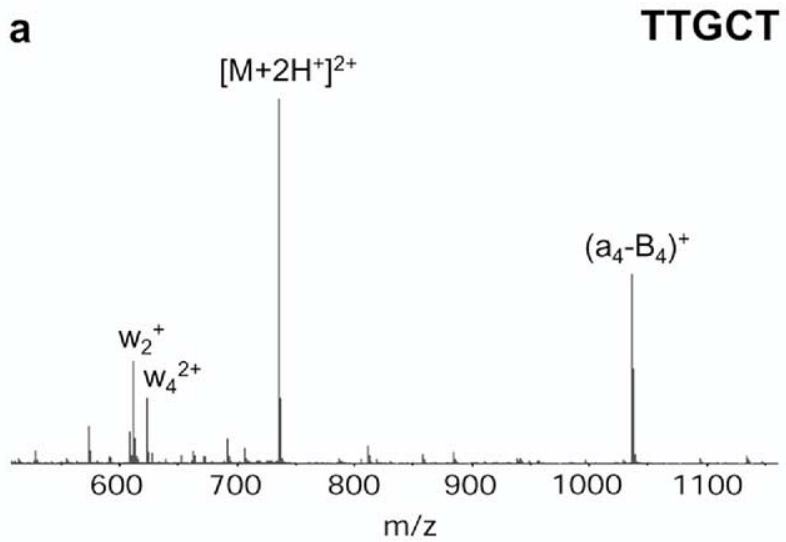

b
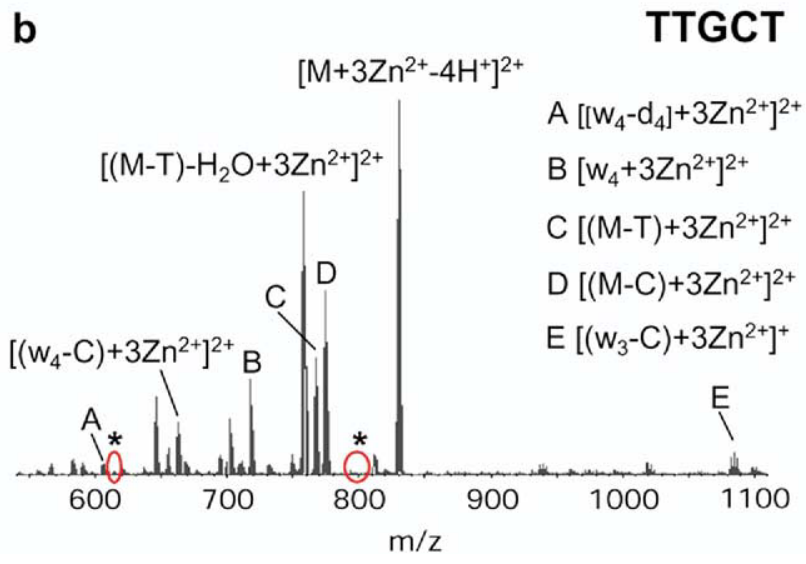

Figure 2. Comparison of the product ion spectra of [TTGCT + $\left.2 \mathrm{H}^{+}\right]^{2+}(\mathbf{a})$ and $\left[\mathrm{TTGCT}+3 \mathrm{Zn}^{2+}-4 \mathrm{H}^{+}\right]^{2+}(\mathbf{b})$. The intensive peak the of $\mathrm{w}_{2}$-fragment visible in the spectrum of the uncomplexed oligonucleotide is not detected in the spectrum of the $\left[\mathrm{Zn}^{2+}\right]_{3}$ complex, neither in the uncomplexed nor in the metal-complexed form (asterisks). On the other hand, the abundant peaks of the M-B-ions of the $\left[\mathrm{Zn}^{2+}\right]_{3}$-complex in the spectrum of the uncomplexed oligonucleotide lack, whereas abundant peaks of the $\mathrm{w}_{4}$-ion are visible in both spectra. All ions labeled in the spectrum of $\left[\mathrm{Zn}^{2+}\right]_{3}$-TTGCT (b) bear all three $\mathrm{Zn}^{2+}$-ions, as proven by the characteristic isotopic pattern.

bear three metal ions, identical to the number of metal ions coordinated to their precursor. A few low-mass fragments, which do not show any metal-coordination at all, can be found as well. Yet, no fragment ions descending from a triply complexed precursor ion coordinating only one or two metal ions have been identified, thus proving that the bonds formed between metal ions and oligonucleotide are very strong. This is demonstrated by the spectrum in Figure 3a. By forming such strong complexes, the metal ions effect a stabilization, particularly of the phosphate-backbone, changing the fragmentation pattern of the complexes compared to the fragmentation pattern of bare oligonucleotides, as described above. Such an effect seems to be a characteristic property of the transition metal investigated, and does not apply to metal-oligonucleotide complexes in general, as a comparative CID experiment with a $\left[\mathrm{Na}^{+}\right]_{6}$-pentamer complex impressively revealed. In contrast to the dissociation of transition metal ion 
a

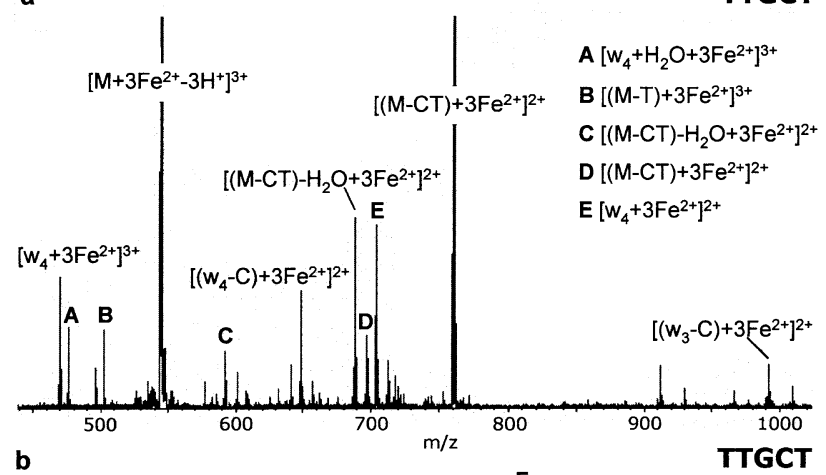

b

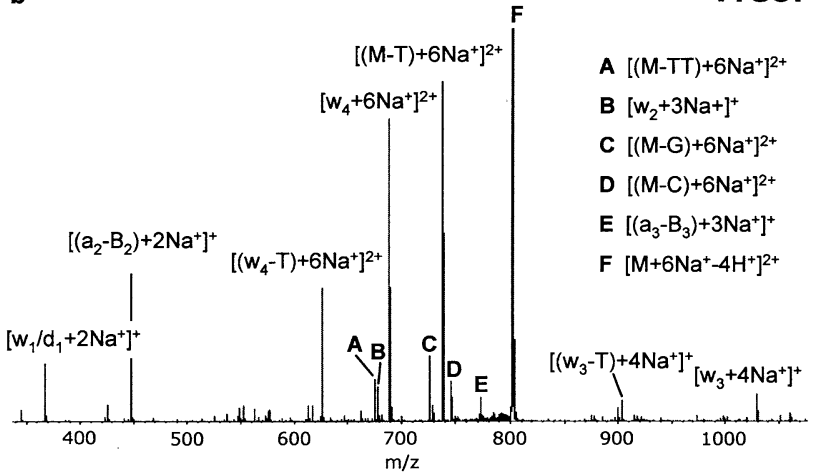

Figure 3. (a) CID spectrum of $\left[\mathrm{TTGCT}+3 \mathrm{Fe}^{2+}-3 \mathrm{H}^{+}\right]^{3+}$. Every fragment coordinates exactly three $\mathrm{Fe}^{2+}$-ions, identical to the number of iron ions complexed in the precursor ion. Consequently, very strong bonds are formed between oligonucleotide and metal ions, as metal ions are not released upon CID. This behavior is a characteristic property of the metal-oligonucleotide complexes investigated in this study. (b) CID spectrum of [TTGCT $\left.+6 \mathrm{Na}^{+}-4 \mathrm{H}^{+}\right]^{2+}$. In contrast to spectrum in Figure $3 \mathrm{a}$, the number of $\mathrm{Na}^{+}$-adducts corresponds to the length of the respective fragment but is independent of the precursor ion. Consequently, there is no stabilizing effect and the fragmentation pattern resembles rather the one of an uncomplexed oligonucleotide.

complexes, fragments with a varying number of metal ions are generated. The number of sodium ions on a fragment ion is chiefly controlled by the length of the fragment, but independent of the total number of metal ions coordinated to its precursor ion (Figure 3b). Sodium is not able to form nearly as strong bonds as the three transition metals investigated. Hence, there is no stabilizing effect and the fragmentation pattern of a sodium-oligonucleotide complex resembles more the one of an uncomplexed oligonucleotide.

The Effect of $\mathrm{Fe}^{3+}, \mathrm{Fe}^{2+}$, and $\mathrm{Zn}^{2+}$ on the Fragmentation of Four Model Pentamers and Their Localization by Analysis of Given Fragments

Studying the behavior of metal-oligonucleotide complexes in the positive ion mode by tandem mass spectrometry is a step into a hardly discovered area. Interpretation of analytical data is strongly complicated by the large diversity of complexes generated. The diversity due to the combination of different metal ions with oligonucleotides is further increased by the varying number of coordinated metal ions and resulting charge states. Localization of metal ions within the oligonucleotides is performed by identifying the shortest metalcomplexed fragment ions from the $5^{\prime}$ - and the $3^{\prime}$-end. The overlapping portion of the two oppositely directed partial sequences is the metal-binding part of the oligonucleotide. This strategy of localization is supported by the few short uncomplexed fragments and the remaining longer metal-complexed fragment ions.

\section{Dissociation of Uncomplexed Pentanucleotides $[\mathrm{M}+2 \mathrm{H}]^{2+}$}

Protonation of the nucleobase is the key step initiating base loss and subsequent backbone dissociation of deprotonated oligodeoxynucleotides [30, 31] and there is evidence that the same mechanism applies to protonated oligodeoxynucleotides as well. Although the corresponding product ion spectra are not entirely identical, dissociation of both positively and negatively charged precursor ions results in characteristic $\mathrm{w}$ - and (a-B)-ions [32] of various length as the most abundant fragment ions. This observation is in agreement with other studies on protonated oligonucleotides [26-28].

The most abundant peaks in the spectra of uncomplexed oligonucleotides arise from $\mathrm{w}_{2}-,\left(\mathrm{a}_{4}-\mathrm{B}_{4}\right)^{-}$and $\mathrm{w}_{4}$-ions. As illustrated in Figure 4, the dissociation of the molecule occurs between all nucleotides. However, the abundances of the dominant fragment ions differ between the spectra of the four oligonucleotides studied, as shown by the relative abundance of the $\left(\mathrm{a}_{4}-\mathrm{B}_{4}\right)$ ion in the spectra of TTCAT, TTGAT, TTGCT, and TTGGT. In the spectra of TTGGT and TTGCT, the

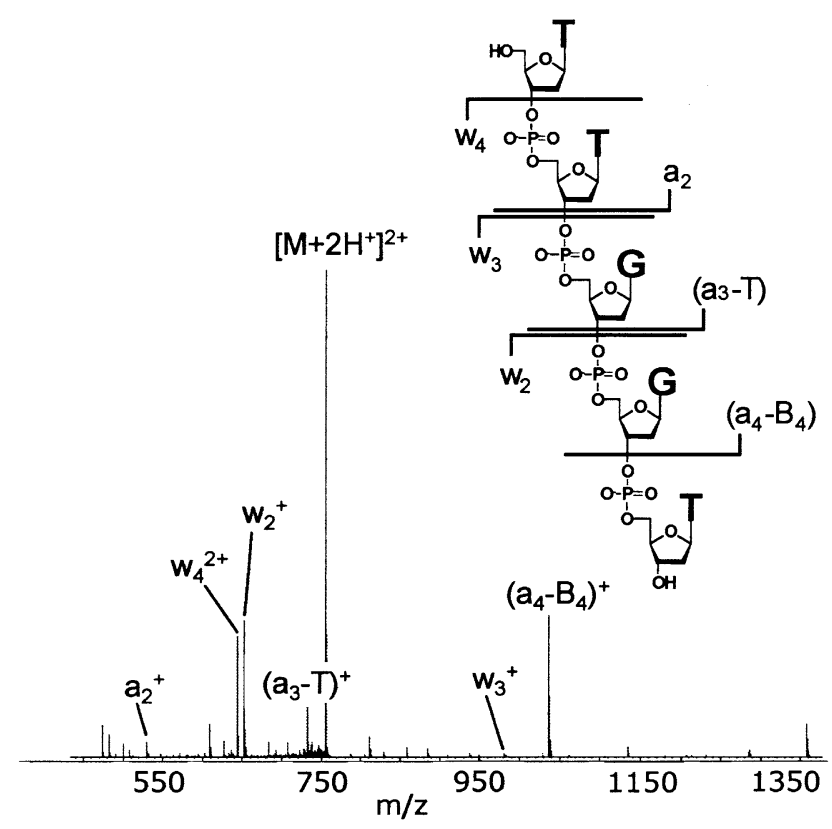

Figure 4. Product ion spectrum of $\left[\text { TTGGT }+2 \mathrm{H}^{+}\right]^{2+}$. The most intensive peaks arise from the $\mathrm{w}_{2^{-}}, \mathrm{w}_{4^{-}}$, and $\left(\mathrm{a}_{4}-\mathrm{B}_{4}\right)$-fragment. Upon CID the oligonucleotide dissociates between all nucleotides, giving fragments of varying lengths. 
a
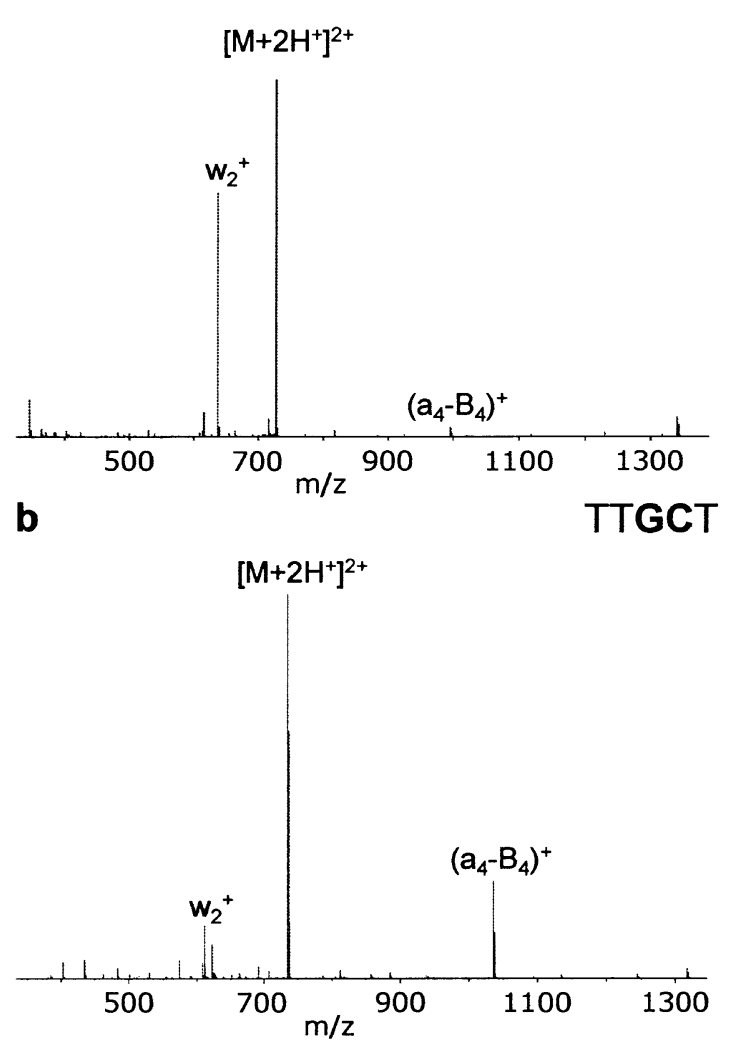

Figure 5. Sequence dependence of the fragmentation on the example of two uncomplexed oligonucleotides. While the oligonucleotide of the sequence TTCAT shows the $\mathrm{w}_{2}$-ion with high and the $\left(\mathrm{a}_{4}-\mathrm{B}_{4}\right)$-ion only with significantly lower abundance than $\mathrm{w}_{2}(\mathbf{a})$, the opposite is true for the oligonucleotide TTGCT (b).

$\left(\mathrm{a}_{4}-\mathrm{B}_{4}\right)$-ion occurs with very high abundance, which even exceeds the generally abundant $\mathrm{w}_{2}$-ion. Opposite behavior was found for TTGAT and TTCAT. Here, the $\mathrm{w}_{2}$-ion shows the highest abundance and the $\left(\mathrm{a}_{4}-\mathrm{B}_{4}\right)$-ion appears only with average intensity comparable to other fragments (Figure 5). The most evident difference between the two pairs of pentanucleotides, which exhibit such diverse fragmentation behavior, is the presence of adenine within TTGAT and TTCAT and its absence in TTGGT and TTGCT. This observation strongly implies that the base sequence of the oligonucleotides does affect the fragmentation.

Dissociation of $\left[\mathrm{M}+\mathrm{Fe}^{3+}-\mathrm{H}^{+}\right]^{2+}$

By adding $\mathrm{FeCl}_{3}$ to the oligonucleotides in solution, iron-oligonucleotide complexes are generated. Complexes of pentanucleotides with one or two $\mathrm{Fe}^{3+}$-ions are observed. Generally, complexes bearing a single $\mathrm{Fe}^{3+}$-ion exhibit higher abundance and have been selected for further investigation. The product ion spectra of the four complexes investigated show the metal-complexed $\mathrm{w}_{4}$-ion with highest abundance. Metal-complexed $\left(\mathrm{w}_{4}-\mathrm{B}\right), \mathrm{M}-\mathrm{B}$ and the core fragment $\left[\mathrm{w}_{4}-\mathrm{d}_{4}\right]$ lead to abundant peaks as well, whereas the $\mathrm{w}_{2}$-ion, which is very abundant in the product ion spectra of the bare oligonucleotides, is not detected any more, either in metal-complexed, or in uncomplexed form. Also, the abundance of the dominant $\left(\mathrm{a}_{4}-\mathrm{B}_{4}\right)$-ions observed in the spectra of uncomplexed TTGCT and TTGGT has remarkably decreased in the product ion spectra of the $\mathrm{Fe}^{3+}$-complexed oligonucleotides. In their $\mathrm{Fe}^{3+}$-complexed form, the $\left(\mathrm{a}_{4}-\mathrm{B}_{4}\right)$ ions appear to a reduced amount only. Besides the metal-complexed fragments, the uncomplexed $a_{2}$ and $z_{2}$-ions, $a_{1^{-}} / z_{1^{-}}, c_{1}-/ x_{1^{-}}$, and nucleoside-like ions with $m / z$ 192, 207, 216, and 232, whose structures have been proposed previously [27, 28], are detected as well. The presence of the iron-containing $\left[\mathrm{w}_{4}-\mathrm{d}_{4}\right]$ core fragment (Scheme 1) in the spectra of all four pentamers suggests that the $\mathrm{Fe}^{3+}$-ion has a stabilizing effect on the phosphate backbone. This is reflected by the lack of short metal-adducted fragments and the frequent loss of nucleobases. Thus, the presence of the $\mathrm{Fe}^{3+}$-ion clearly alters the fragmentation pathway and enhances the formation of characteristic metalcontaining fragments, as demonstrated by the product ion spectrum of $\left[\text { TTGAT }+\mathrm{Fe}^{3+}-\mathrm{H}^{+}\right]^{2+}$ in Figure 6.

Identification of the shortest metal-complexed fragment ions from the $5^{\prime}$ - and the $3^{\prime}$-end enables the localization of the $\mathrm{Fe}^{3+}$-ion within the oligonucleotide. Simultaneous occurrence of the metal-complexed fragments $\left(w_{3}-B_{3}\right) /\left(w_{3}-B_{4}\right)$, and $\left(a_{3}-B_{3}\right)$ within in the product ion spectra of all four pentamers restricts the position of the $\mathrm{Fe}^{3+}$-ion to the third nucleotide from the 3 '-end (Figure 7). Since the nonterminal sugar residues do not provide any suitable binding site for metal ions, the $\mathrm{Fe}^{3+}$-ion must coordinate either to nucleobase $\mathrm{B}_{3}$ or to the adjacent phosphate group. Binding of the $\mathrm{Fe}^{3+}$. ion to the third nucleobase $B_{3}$ can clearly be excluded, as the metal-complexed $\left(a_{3}-B_{3}\right)$-ions are present in the spectra of all four $\mathrm{Fe}^{3+}$-pentamer complexes studied. Further evidence is given by detection of the complementary metal-complexed $\left(\mathrm{w}_{3}-\mathrm{B}_{3}\right)$-ions, confirming that nucleobase $B_{3}$ is not involved in complexation of the

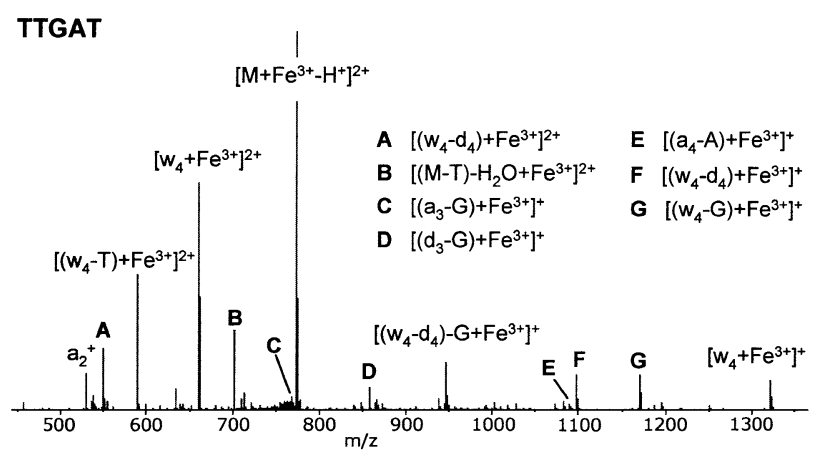

Figure 6. CID spectrum of the complex $\left[\text { TTGAT }+\mathrm{Fe}^{3+}-\mathrm{H}^{+}\right]^{2+}$. All intensive peaks correspond to fragments with a minimum length of three nucleoside units and bear the $\mathrm{Fe}^{3+}$-ion. The only exception is the fragment $a_{2}$ which is shorter and also lacks the metal-ion. Specific for the metal-oligonucleotide complex is further the core fragment $\left[\mathrm{w}_{4}-\mathrm{d}_{4}\right]$. 


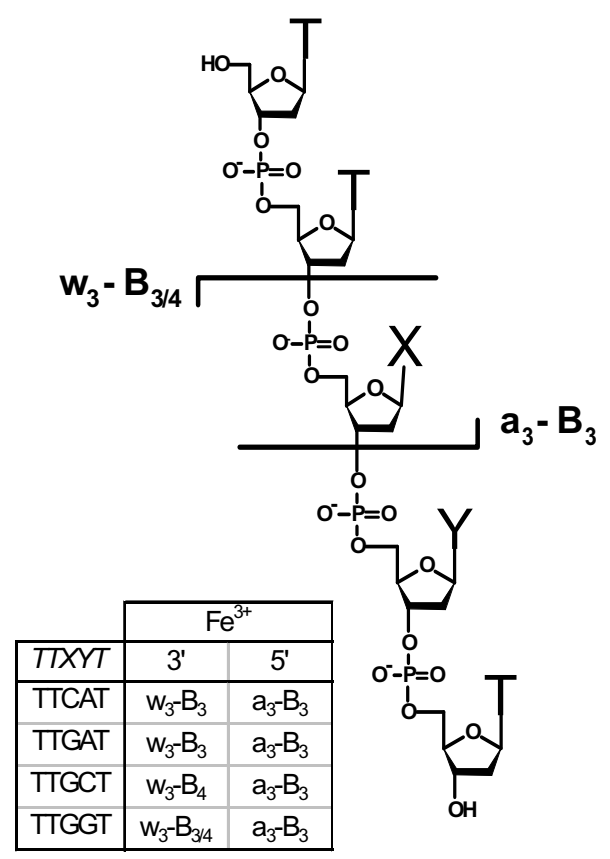

Figure 7. Localization of the $\mathrm{Fe}^{3+}$-ion within the four pentamers. The $\left(\mathrm{a}_{3}-\mathrm{B}_{3}\right)$-ions are the shortest $5^{\prime}$-fragments and the $\mathrm{w}_{3}-\mathrm{B}_{3 / 4}$-ions are the shortest $3^{\prime}$-fragments coordinating the $\mathrm{Fe}^{3+}$-ion. Consequently the $\mathrm{Fe}^{3+}$-ion must be located in the center of the molecule, on the second phosphate group from the $5^{\prime}$-end.

$\mathrm{Fe}^{3+}$-ion. Based on these observations we can conclude that the metal ion must be associated with the phosphate group and consequently, for the pentamers studied, we can accurately locate the $\mathrm{Fe}^{3+}$-ion at the second phosphate group from the $5^{\prime}$-end. Also, this finding is in accordance with the observation of uncomplexed $\mathrm{a}_{2}$ and $z_{2}$-fragments (Figure 7 ).

The sequence specific difference between the pentanucleotides TTCAT/TTGAT and TTGGT/TTGCT, observed in the product ion spectra of the bare oligonucleotides, does not appear if the oligonucleotides are coordinated with a $\mathrm{Fe}^{3+}$-ion. Here, the $\mathrm{w}_{4}$-ion is of highest abundance within the spectra of all four $\mathrm{Fe}^{3+}$ oligonucleotide complexes and the abundant metalcomplexed $\left(\mathrm{w}_{4}-\mathrm{B}\right)^{-},(\mathrm{M}-\mathrm{B})-$, and $\left[\mathrm{w}_{4}-\mathrm{d}_{4}\right]$-ions do not give any evidence for a sequence specific fragmentation behavior. Thus, the $\mathrm{Fe}^{3+}$-ion coordinating to the center of the molecule obviously suspends the influence of the nucleobase sequence.

\section{Dissociation of $\left[\mathrm{M}+3 \mathrm{Fe}^{2+}-3 \mathrm{H}^{+}\right]^{3+}$}

Investigating the product ion spectra of triply $\mathrm{Fe}^{2+}$ coordinated pentamers reveals three remarkable facts. First, all fragment ions appear exclusively in the metalcomplexed form, which is confirmed by the calculated molecular weights and by the characteristic isotopic patterns of iron-adducted fragments. Second, the complementary fragments, e.g., $\mathrm{a}_{2}$ or $\left(\mathrm{a}_{2}-\mathrm{B}_{2}\right)$ as counterparts to $\left(w_{3}-B\right)$, are absent. In the range below $m / z 400$, peaks corresponding to the released nucleobases and the uncomplexed nucleoside-like ions with $m / z 192$ and $m / z$ 232 are visible [27, 28]. The third, rather unexpected observation is the complete lack of any $5^{\prime}$-fragments in the product ion spectra of $\left[\mathrm{M}+3 \mathrm{Fe}^{2+}-3 \mathrm{H}^{+}\right]^{3+}$. The disappearance of the $\left(\mathrm{a}_{4}-\mathrm{B}_{4}\right)$-fragment ion, which was present in the product ion spectra of both the uncomplexed and the $\mathrm{Fe}^{3+}$-complexed pentamers, is remarkable. This behavior can most likely be assigned to a fundamental change in the fragmentation pathway caused by the complexation with metal ions.

The absence of uncomplexed counterions renders the localization of the binding sites of the three $\mathrm{Fe}^{2+}$-ions more difficult than the localization of the single $\mathrm{Fe}^{3+}$-ion demonstrated previously. For the four pentamers investigated, the shortest identified metal-coordinated fragments are the $\left(\mathrm{w}_{3}-\mathrm{B}\right)$-ions, thus limiting the binding sites of the metal ions to the three $3^{\prime}$-terminal nucleotide units. A further positional constraint is provided by the observation of the $\left[\mathrm{w}_{4}-\mathrm{d}_{4}\right]$ core fragment, which excludes both the 3 ' - and the 5 '-end as binding sites. Consequently, potential binding sites for the three $\mathrm{Fe}^{2+}$-ions are restricted to the third and fourth nucleotide and the adjacent phosphate group, as shown in Figure 8.

As found previously for the $\mathrm{Fe}^{3+}$-adducted pentamers, $\mathrm{Fe}^{2+}$-ions are also primarily located in the central region of the pentamers, where they stabilize the phosphate-backbone. The frequent loss of nucleobases, indicated by the presence of M-B-, $\left(\mathrm{w}_{4}-\mathrm{B}\right)-$, and $\left(\mathrm{w}_{3}-\mathrm{B}\right)$ -
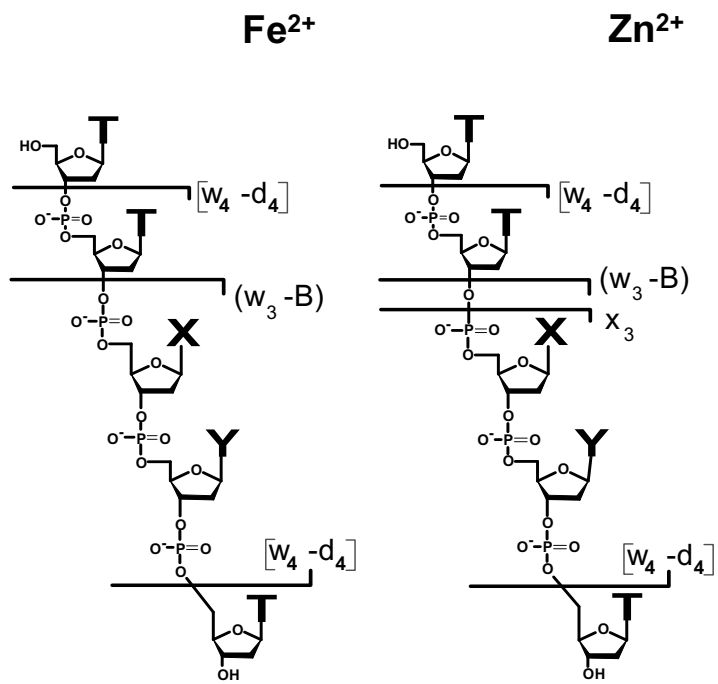

\begin{tabular}{|c|c|c|}
\cline { 2 - 3 } \multicolumn{1}{c|}{} & \multicolumn{2}{c|}{$3 \mathrm{Fe}^{2+}$} \\
\hline TTXYT & $3^{\prime}$ & $5^{\prime}$ \\
\hline TTCAT & $\mathrm{w}_{3}-\mathrm{A} / \mathrm{C}$ & {$\left[\mathrm{w}_{4}-\mathrm{d}_{4}\right]$} \\
\hline TTGAT & $\mathrm{w}_{3}-\mathrm{A} / \mathrm{[}$ & {$\left[\mathrm{w}_{4}-\mathrm{d}_{4}\right]$} \\
\hline TTGCT & $\mathrm{w}_{3}-\mathrm{C}$ & {$\left[\mathrm{w}_{4}-\mathrm{d}_{4}\right]$} \\
\hline TTGGT & $\mathrm{w}_{3}-\mathrm{G}$ & {$\left[\mathrm{w}_{4}-\mathrm{d}_{4}\right]$} \\
\hline
\end{tabular}

\begin{tabular}{|c|c|c|}
\cline { 2 - 3 } \multicolumn{1}{c|}{} & \multicolumn{2}{c|}{$3 \mathrm{Zn}^{2+}$} \\
\hline TTXYT & $3^{\prime}$ & $5^{\prime}$ \\
\hline TTCAT & $\mathrm{w}_{3}-\mathrm{C}$ & {$\left[\mathrm{w}_{4}-\mathrm{d}_{4}\right]$} \\
\hline TTGAT & $\mathrm{w}_{3}-\mathrm{A}$ & {$\left[\mathrm{w}_{4}-\mathrm{d}_{4}\right]$} \\
\hline TTGCT & $\mathrm{w}_{3}-\mathrm{C}$ & {$\left[\mathrm{w}_{4}-\mathrm{d}_{4}\right]$} \\
\hline TTGGT & $\mathrm{x}_{3}$ & {$\left[\mathrm{w}_{4}-\mathrm{d}_{4}\right]$} \\
\hline
\end{tabular}

Figure 8. [TTXYT $\left.+3 \mathrm{M}^{2+}\right]$. Localization of the three $\mathrm{Fe}^{2+} / \mathrm{Zn}^{2+}$ ions within the four pentamers. The shortest $3^{\prime}$ - and $5^{\prime}$-fragments which coordinate the metal ions are listed and marked with a bar. For details see text. 
fragments, strongly suggests that the primary binding sites of the metal ions are the phosphate groups of the backbone and not the nucleobases. However, experiments with $\left[\mathrm{Fe}^{2+}\right]_{4}$-pentamer complexes and the detection of a fivefold $\mathrm{Fe}^{2+}$-complexed pentamer (data not shown) suggest that the nucleobases can as well be involved in the binding of metal ions, since coordination of more than one doubly-charged metal ion per phosphate group seems utmost unlikely due to the resulting coulombic interactions. Therefore, we conclude that all available phosphate groups are predominantly occupied by $\mathrm{Fe}^{2+}$-ions and if additional binding sites are required, the nucleobases can serve as binding sites too.

Different behavior of TTCAT/TTGAT on the one side and TTGCT/TTGGT on the other side, which was observed previously for uncomplexed oligonucleotides, is also found for the $\left[\mathrm{Fe}^{2+}\right]_{3}$-pentamer complexes. Here, the difference is reflected by the abundance of metalcomplexed $\mathrm{w}_{4^{-}}$and M-B-ions. Within the sequences TTCAT and TTGAT the generation of $\mathrm{w}_{4}$-ions is strongly favored, followed by M-T-ions. Surprisingly, $\mathrm{M}-\mathrm{C}, \mathrm{M}-\mathrm{G}$, as well as M-A-ions are missing. In contrast to these findings, dissociation of TTGCT and TTGGT primarily generates metal-complexed $\mathrm{M}-\mathrm{C}$ - and M-Gions as the main fragments. Repetitive loss of two nucleobases, resulting in M-C-T- and M-G-T-ions, is registered to a noticeable amount too. These results suggest that the presence of adenine has a destabilizing effect within the pentamers, despite the stabilizing influence of the metal ions coordinated. Dissociation of $\left[\mathrm{M}+3 \mathrm{Zn}^{2+}-4 \mathrm{H}^{+}\right]^{2+}$
and $\left[\mathrm{M}+3 \mathrm{Zn}^{2+}-3 \mathrm{H}^{+}\right]^{3+}$

The spectra of $\left[\mathrm{Zn}^{2+}\right]_{3}$-pentamer complexes show abundant peaks of metal-coordinated $\mathrm{w}_{4}$ - and M-B-ions. To a lesser extent, metal-coordinated $\left(\mathrm{w}_{4}-\mathrm{B}\right)_{-},\left[\mathrm{w}_{4}-\mathrm{d}_{4}\right]_{-}$, and $\left(w_{3}-B\right)$-ions are detected as well. Peak assignment may be hindered by the formation of isobaric $5^{\prime}$ - and $3^{\prime}$-ions. This problem was also encountered in the case of zinc-adducted pentanucleotides, as abundant peaks corresponding to metal-coordinated $\mathrm{c}_{4}-/ \mathrm{x}_{4}$-ions were found in the spectra of $\left[\mathrm{Zn}^{2+}\right]_{3}$-TTGAT and $\left[\mathrm{Zn}^{2+}\right]_{3^{-}}$ TTGGT. Additionally, $a_{4}-/ z_{4}$-ions were observed in the case of $\left[\mathrm{Zn}^{2+}\right]_{3}$-TTGGT. However, the absence of any unambiguously assigned $5^{\prime}$-fragment ion and the presence of the $x_{3}$-fragment ion in the spectrum of $\left[\mathrm{Zn}^{2+}\right]_{3}-$ TTGGT suggests that the fragment ions in question rather derive from the $3^{\prime}$-end, thus, are the $\mathrm{x}_{4}$ - and $\mathrm{z}_{4}$-ions.

Furthermore, short uncomplexed fragment ions are observed, whereof the one with $\mathrm{m} / \mathrm{z} 225 \mathrm{can}$ be assigned to $\mathrm{a}_{1}$, being the counterion to the $\mathrm{w}_{4}$-fragment. Peaks at $\mathrm{m} / \mathrm{z} 192,216$, and 232 correspond to nucleoside-like fragment ions [27, 28]. Fragment ions complementary to metal-coordinated $\left(\mathrm{w}_{3}-\mathrm{B}\right), \mathrm{x}_{3}, \mathrm{x}_{4}$, and $\mathrm{z}_{4}$ are missing.

The localization of the binding sites of $\mathrm{Zn}^{2+}$-ions yields similar results as found for the $\mathrm{Fe}^{2+}$-ions. Based on the observation of the position-defining metal-complexed $\left(\mathrm{w}_{3}-\mathrm{B}_{3}\right)^{-},\left(\mathrm{w}_{3}-\mathrm{B}_{4}\right)^{-}$, and $\left[\mathrm{w}_{4}-\mathrm{d}_{4}\right]$-fragment ions, the binding site of the $\mathrm{Zn}^{2+}$-ions can be assigned to the three $3^{\prime}$-terminal phosphate groups and the two interjacent nucleosides (Figure 8).

Like the iron ions, the zinc ions are also located in the central region of the molecules, exerting a stabilizing effect on the phosphate backbone. There is evidence that the zinc ions coordinate to the phosphate groups. However, the exact binding sites cannot be appointed unambiguously. It stands to question whether nucleobases $B_{3}$ and $B_{4}$ of the interjacent nucleosides are involved in the metal coordination or not. The four $\left[\mathrm{Zn}^{2+}\right]_{3}$-pentamer complexes investigated show neither a base-specific, nor a positionally preferred loss of nucleobases $B_{3}$ and $B_{4}$. Loss of $B_{3}$ from TTCAT is indicated by the $\mathrm{w}_{3}-\mathrm{C}$ fragment ion, and loss of $\mathrm{B}_{4}$ from TTGCT and TTGAT results in the corresponding $\mathrm{w}_{3}-\mathrm{B}_{4}$ fragment ions. In the spectrum of $\left[\mathrm{Zn}^{2+}\right]_{3}$-TTGGT the $\mathrm{w}_{3}-\mathrm{G}$ ion is identified unambiguously. Consequently, no plausible pattern for the binding of $\mathrm{Zn}^{2+}$-ions to the nucleobases $\mathrm{B}_{3}$ and $\mathrm{B}_{4}$ can be established. Such stochastic cleavages strongly indicate that the nucleobases are most unlikely to be involved in the coordination of the zinc ions. Also, in contrast to the observations made for $\mathrm{Fe}^{2+}$-pentamer complexes, no $\left[\mathrm{Zn}^{2+}\right]_{5}$-pentamer complex was generated, indicating that zinc ions are not likely to coordinate to the nucleobases. Therefore, we propose the phosphate groups as the only binding sites for the zinc ions.

The difference between TTCAT/TTGAT and TTGCT/TTGGT, discussed for the bare oligonucleotides and for $\left[\mathrm{Fe}^{2+}\right]_{3}$-pentamer complexes, reappears for the $\left[\mathrm{Zn}^{2+}\right]_{3}$-pentamer complexes. Surprisingly, there is a clear difference between $\left[\mathrm{Fe}^{2+}\right]_{3}$ - and $\left[\mathrm{Zn}^{2+}\right]_{3}$-pentamer complexes. While from the $\left[\mathrm{Fe}^{2+}\right]_{3}$-pentamer complexes mainly guanine and cytosine are cleaved off, giving abundant M-G- and M-C-ions, it is thymine and thymine in combination with water which are released from the $\mathrm{Zn}^{2+}$-complexed oligonucleotides. M-G- and $\mathrm{M}-\mathrm{C}$-ions usually appear to a lesser extent only, except for the quite abundant $\mathrm{M}-\mathrm{C}$-ion in the spectrum of TTGCT. The observed preference for the loss of thymine may be attributed to the terminal position of the thymine bases versus the central position of guanine and cytosine. Despite its significantly lower proton affinity, protonation and subsequent loss of thymine to such an extent is somewhat unexpected.

Comparing the results from $\left[\mathrm{Zn}^{2+}\right]_{3}$-pentamer complexes with the data from $\left[\mathrm{Fe}^{2+}\right]_{3}$-pentamer complexes reveals the different influences of the two doubly charged metal ions on the pentanucleotides.

\section{Conclusions}

Results disclose a set of fundamental aspects of the gas-phase behavior of metal-oligonucleotide complexes. The identity of the metal ions and the base 
sequences of the oligonucleotides both noticeably direct the fragmentation of the metal-oligonucleotide complexes upon CID. Assignment of metal-coordinated fragment ions and the appearance of terminal metalfree fragment ions provide new insight into the binding patterns of the three selected transition metals.

\section{$\mathrm{Fe}^{3+}$-complexes:}

The coordination of a single $\mathrm{Fe}^{3+}$-ion to a pentanucleotide results in a significant change of the fragmentation of the newly formed complex. The binding site of the $\mathrm{Fe}^{3+}$-ion can unambiguously be appointed to the second phosphate group from the 5 '-end of all four pentanucleotides investigated. Involvement of the nucleobases in the coordination of the metal ion is clearly excluded.

$\mathrm{Fe}^{2+}$-complexes:

Investigation of $\left[\mathrm{Fe}^{2+}\right]_{3}$-pentanucleotide complexes exclusively reveals metal-complexed 3 '-terminal fragment ions and the three $\mathrm{Fe}^{2+}$-ions can be located at the three $3^{\prime}$-terminal phosphate groups. On the basis of additional experiments on $\left[\mathrm{Fe}^{2+}\right]_{5}$-pentanucleotide complexes it can be assumed that $\mathrm{Fe}^{2+}$-ions predominantly occupy phosphate groups of the oligonucleotide backbone. If no further phosphates are available and additional binding sites are required, the nucleobases can serve as binding sites as well.

\section{$\mathrm{Zn}^{2+}$-complexes:}

Experiments revealed the phosphate groups of the oligonucleotide backbone as the binding sites for $\mathrm{Zn}^{2+}$ ions. Unlike for iron complexes, participation of the nucleobases in the binding of zinc ions in $\left[\mathrm{Zn}^{2+}\right]_{3}$ complexes cannot be excluded unambiguously.

This study demonstrates the potential of tandem mass spectrometry for characterizing noncovalent interactions between oligonucleotides and metal ions. Once the fundamental aspects of gas-phase dissociation of metal-oligonucleotide complexes are better understood, it should prove possible to characterize the binding motifs and binding stoichiometries of metal ions, and consequently, to gain deeper insight into the concepts of metal ion coordination to oligonucleotides.

\section{Acknowledgments}

The authors thank the Swiss National Science Foundation for generous financial support of this project (grant no. 200021100684).

\section{References}

1. Eichhorn, G. L. In Inorganic Biochemistry, Vol. 2, Eichhorn, G. L., Ed. Elsevier Scientific Publishing Company: Amsterdam, 1973; pp 1210-1243.

2. Lippard, S. J.; Berg, J. M. Bioanorganische Chemie; Spektrum Akademischer Verlag: Heidelberg, Berlin, Oxford, 1995; p 16.
3. Pyle, A. M. Ribozymes: A Distinct Class of Metalloenzymes. Science 1993, 261, 709-714.

4. Lippard, S. J.; Berg, J. M. Bioanorganische Chemie; Spektrum Akademischer Verlag: Heidelberg, Berlin, Oxford, 1995; pp 16, 209-211.

5. Cowan, J. A. Inorganic Biochemistry: An Introduction, 2nd ed.; Wiley-VHC: New York, 1997; pp 257-290.

6. Reyzer, M. L.; Brodbelt, J. S.; Kerwin, S. M.; Kumar, D. Evaluation of Complexation of Metal-Mediated DNA-Binding Drugs to Oligonucleotides via Electrospray Ionization Mass Spectrometry. Nucleic Acids Res. 2001, 29, E103-3.

7. Hagemeister, T.; Linscheid, M. Mass Spectrometry of cisDiamminedichloroplatinum(II) Adducts to the Dinucleosidemonophosphates d(ApG), d(GpG), and $\mathrm{d}(\mathrm{TpC})$ in an Ion Trap. J. Mass. Spectrom. 2002, 37, 731-747.

8. Browne, K. A. Metal Ion-Catalyzed Nucleic Acid Alkylation and Fragmentation. J. Am. Chem. Soc. 2002, 124, 7950-7962.

9. Franklin, S. J. Lanthanide-Mediated DNA Hydrolysis. Curr. Opin. Chem. Biol. Rev. 2001, 5, 201-208.

10. Schnaith, L. M.; Hanson, R. S.; Que, L., Jr. Double-Stranded Cleavage of pBR322 by a Diiron Complex via a "Hydrolytic" Mechanism. Proc. Natl. Acad. Sci. U.S.A. 1994, 91, 569-573.

11. Lempers, E. L.; Bashkin, J. S.; Kostic, N. M. A New Trinuclear Complex of Platinum and Iron Efficiently Promotes Cleavage of Plasmid DNA. Nucleic Acids Res. 1993, 21, 1983-1990.

12. Yamashita, A.; Tawa, R.; Imakura, Y.; Lee, K. H.; Sakurai, H. Site-Specific DNA Cleavage by $\mathrm{Cu}(\mathrm{II})$ Complexes of Podophyllotoxin Derivatives. Biochem. Pharmacol. 1994, 47, 19201925.

13. Haener, R.; Huesken, D.; Hall, J. Development of Artificial Ribonucleases Using Macrocyclic Lanthanide Complexes. Chimia 2000, 54, 569-573.

14. Wu, Q.; Cheng, X.; Hofstadler, S. A.; Smith, R. D. Specific Metal-Oligonucleotide Binding Studied by High Resolution Tandem Mass Spectrometry. J. Mass Spectrom. 1996, 31, 669_ 675 .

15. Froystein, N. A.; Davis, J. T.; Reid, B. R.; Sletten, E. SequenceSelective Metal Ion Binding to DNA Oligonucleotides. Acta Chem. Scand. 1993, 47(7), 49-57.

16. Froystein, N. A.; Sletten, E. The Binding of Manganese(II) and Zinc(II) to the Synthetic Oligonucleotide d(C-G-C-G-A-A-T-TC-G-C-G)2. A 1H NMR Study. Acta Chem. Scand. 1991, 45, 219-225.

17. Froystein, N. A.; Sletten, E. The Interaction of Mercury(II) with the DNA Dodecamer CGCGAATTCGCG. A 1H and 15N NMR Study. J. Am. Chem. Soc. 1994, 116, 3240-3250.

18. Christian, N. P.; Giver, L. J.; Ellington, A. D.; Reilly, J. P. Effects of Matrix Variations and the Presence of Iron on MALDI Mass Spectra of DNA. Rapid Commun. Mass Spectrom. 1996, 10(15), 1980-1986.

19. Wang, Y.; Taylor, J. S.; Gross, M. L. Fragmentation of Electrospray-Produced Oligodeoxynucleotide Ions Adducted to Metal Ions. J. Am. Soc. Mass Spectrom. 2001, 12(5), 550-556.

20. Favre, A.; Gonnet, F.; Tabet, J.-C. Location of $\mathrm{Na}^{+}$Cation in Negative Ions of DNA Evidenced by Using MS2 Experiments in Ion Trap Mass Spectrometry. Int. J. Mass Spectrom. 1999, 190/191, 303-312.

21. Xiang, Y.; Abliz, Z.; Takayama, M. Cleavage Reactions of the Complex Ions Derived from Self-Complementary Deoxydinucleotides and Alkali-Metal Ions Using Positive Ion Electrospray Ionization with Tandem Mass Spectrometry. J. Am. Soc. Mass Spectrom. 2004, 15(5), 689-696.

22. Hettich, R. L. Formation and Characterization of Iron-Ooligonucleotide Complexes with Matrix-Assisted Laser Desorption/Ionization Fourier Transform Ion Cyclotron Resonance 
Mass Spectrometry. J. Am. Soc. Mass Spectrom. 1999, 10(10), 941-949.

23. Hettich, R. L. Investigating the Effect of Transition Metal Ion Oxidation State on Oligodeoxribonucleotide Binding by MatrixAssisted Laser Desorption/Ionization Fourier Transform Ion Cyclotron Resonance Mass Spectrometry. Int. J. Mass Spectrom. 2001, 204, 55-75.

24. Sannes-Lowery, K. A.; Mack, D. P.; Hu, P.; Mei, H.-Y.; Loo, J. A. Positive Ion Electrospray Ionization Mass Spectrometry of Oligonucleotides. J. Am. Soc. Mass Spectrom. 1997, 8(1), 90-95.

25. Potier N.; Van Dorsselaer A.; Cordier Y.; Roch O.; Bischoff, R. Negative Electrospray Ionization Mass Spectrometry of Synthetic and Chemically Modified Oligonucleotides. Nucleic Acids Res. 1994, 22, 3895-3903.

26. Gross, J.; Leisner, A.; Hillenkamp, F.; Hahner, S.; Karas, M.; Schäfer, J.; Lützenkirchen, F.; Nordhoff, E. Investigations of the Metastable Decay of DNA under Ultraviolet MatrixAssisted Laser Desorption/Ionization Conditions with PostSource-Decay Analysis and Hydrogen/Deuterium Exchange. J. Am. Soc. Mass Spectrom. 1998, 9(9), 866-878.

27. Wang, P.; Bartlett, M. G.; Martin, L. B. Electrospray CollisionInduced Dissociation Mass Spectra of Positively Charged
Oligonucleotides. Rapid Commun. Mass Spectrom. 1997, 11(8), $846-856$.

28. Ni, J.; Mathews, M. A. A.; McCloskey, J. A. Collision-Induced Dissociation of Polyprotonated Oligonucleotides Produced by Electrospray Ionization. Rapid Commun. Mass Spectrom. 1997, 11(6), 535-540.

29. Weimann, A.; Iannitti-Tito, P.; Sheil, M. M. Characterization of Product Ions in High Energy Tandem Mass Spectra of Protonated Oligonucleotides Formed by Electrospray Ionization. Int. J. Mass Spectrom. 2000, 194, 269-288.

30. Wang, Z.; Wan, K. X.; Ramanathan, R.; Taylor, J. S.; Gross, M. L. Structure and Fragmentation Mechanisms of Isomeric T-Rich Oligodeoxynucleotides: A Comparison of Four Tandem Mass Spectrometric Methods. J. Am. Soc. Mass Spectrom. 998, 9(7), 683-691.

31. Wan, K. X.; Gross, M. L. Fragmentation Mechanisms of Oligodeoxynucleotides: Effects of Replacing Phosphates with Methylphosphonates and Thymines with Other Bases in TRich Sequences. J. Am. Soc. Mass Spectrom. 2001, 12(5), 580589.

32. McLuckey, S. A.; Van Berkel, G. J.; Glish, G. L. Tandem Mass Spectrometry of Small, Multiply Charged Oligonucleotides. J. Am. Soc. Mass Spectrom. 1992, 3(1), 60-70. 